\title{
Medical Image of the Week: Azygous Lobe
}

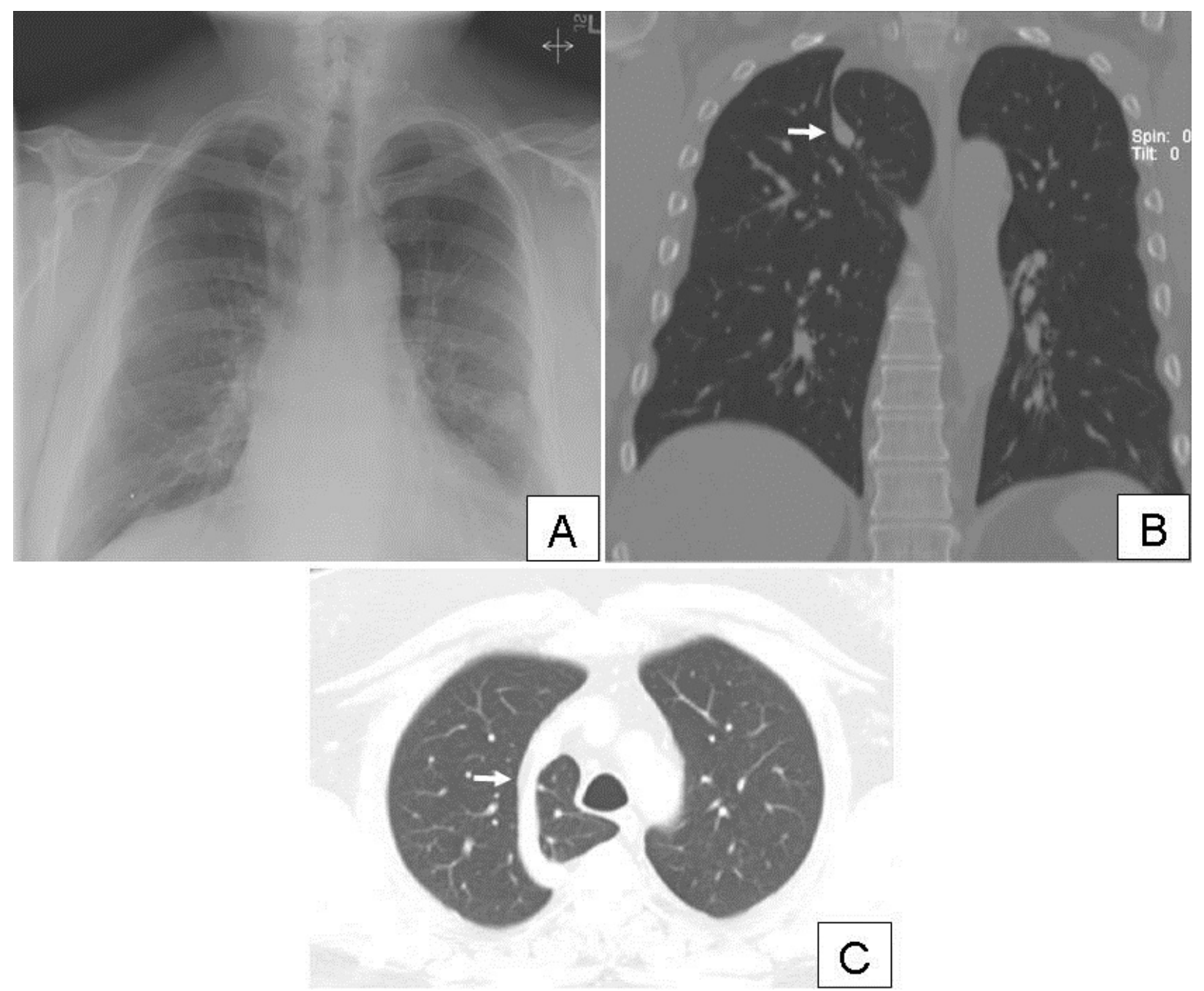

Figure 1. Chest X-Ray (A) and thoracic CT scan (B) show the azygos fissure and the 'tadpole' appearance (arrow). Chest CT (C) shows the lateral course of the azygos vein (arrow) and the accessory lobe.

A 59 year old man underwent chest radiography for evaluation of fever and cough. Imaging showed an accessory azygous lobe. An azygos lobe is found in 1\% of anatomic specimens and forms when the right posterior cardinal vein, one of the precursors of the azygos vein, fails to migrate over the apex of the lung (1). Instead, the vein penetrates the lung carrying along pleural layers that entrap a portion of the right upper lobe. The vein appears to run within the lung, but is actually surrounded by both parietal and visceral pleura. The azygos fissure therefore consists of four layers of pleura, two parietal layers and two visceral layers, which wrap around the vein giving the appearance of a tadpole. Apart from an interesting incidental radiological finding, it is of limited clinical importance except that its presence should be recognized during 
thoracoscopic procedures. This patient was found to have a cavitary lung lesion which was the cause of his symptoms.

Bhupinder Natt MD, Abdulmagid Eddib MD, Dena H'Leureux MD Department of Pulmonary, Allergy, Critical Care and Sleep Medicine University of Arizona and the Southern Arizona VA Health Care System Tucson, AZ

\section{Reference}

Mata J, Cáceres J, Alegret X, Coscojuela P, De Marcos JA. Imaging of the azygos lobe: normal anatomy and variations. AJR Am J Roentgenol. 1991;156(5):931-7. [CrossRef] [PubMed] 